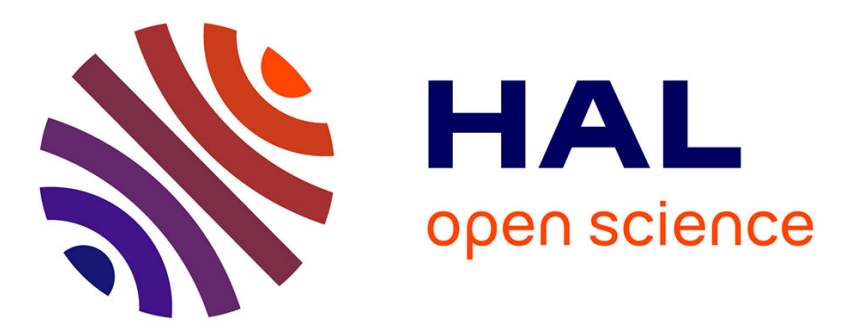

\title{
A simple method to calculate average spectra of clear sky solar radiation and their dependence on the atmospheric parameters
}

\author{
U. Amato, V. Cuomo, R. Guzzi, M. Macchiato, R. Rizzi, C. Serio
}

\section{To cite this version:}

U. Amato, V. Cuomo, R. Guzzi, M. Macchiato, R. Rizzi, et al.. A simple method to calculate average spectra of clear sky solar radiation and their dependence on the atmospheric parameters. Revue de Physique Appliquée, 1985, 20 (2), pp.109-120. 10.1051/rphysap:01985002002010900 . jpa-00245304

HAL Id: jpa-00245304

https://hal.science/jpa-00245304

Submitted on 1 Jan 1985

HAL is a multi-disciplinary open access archive for the deposit and dissemination of scientific research documents, whether they are published or not. The documents may come from teaching and research institutions in France or abroad, or from public or private research centers.
L'archive ouverte pluridisciplinaire HAL, est destinée au dépôt et à la diffusion de documents scientifiques de niveau recherche, publiés ou non, émanant des établissements d'enseignement et de recherche français ou étrangers, des laboratoires publics ou privés. 
Classification

Physics Abstracts

94.40

\title{
A simple method to calculate average spectra of clear sky solar radiation and their dependence on the atmospheric parameters
}

\author{
U. Amato $\left(^{*}\right)$, V. Cuomo $(*)$, R. Guzzi $\left({ }^{* *}\right)$, M. Macchiato $\left({ }^{+}\right)$, R. Rizzi $\left(^{++}\right)$and C. Serio $\left({ }^{*}\right)$ \\ (*) Istituto di Fisica, Facoltà di Ingegneria, Università di Napoli, Napoli, Italy \\ $\left({ }^{+}\right)$Istituto di Fisica Sperimentale, Facoltà di Scienze, Università di Napoli, Napoli, Italy \\ $\left(^{* *}\right)$ G.N.S.M., Istituto di Fisica, Ferrara, Italy \\ $\left({ }^{++}\right)$Istituto di Geofisica, Università di Bologna, Bologna, Italy
}

(Reçu le 15 juin 1984, accepté le 24 octobre 1984)

\begin{abstract}
Résumé. - Il existe de nombreuses méthodes pour calculer le spectre instantané de la radiance dans le cas d'un ciel serein. Ces méthodes nécessitent la connaissance de quelques paramètres atmosphériques comme la turbidité, l'épaisseur optique de la vapeur d'eau et de l'ozone. Toutefois, pour de nombreuses applications, il est plus utile de connaître le spectre moyen sur une longue période. Dans cet article nous introduisons et analysons une méthode simplifiée pour calculer la radiance spectrale moyenne avec une erreur inférieure à $2 \%$. Nous analysons, entre autre la dépendance de la radiance spectrale moyenne journalière des paramètres atmosphériques et saisonniers (c'est-à-dire de la masse d'air).
\end{abstract}

\begin{abstract}
There are several models to compute instantaneous clear sky solar radiation and they require the precise knowledge of meteorologically relevant parameters as the turbidity and the optical thickness of water vapour and ozone. However, in many cases only a mean radiance spectrum is wanted. In this paper we introduce and analyse a simplified method which permits to calculate the daily average radiance spectrum with an error less than $2 \%$. The dependence of the daily radiance spectrum on the atmospheric parameters and on the season is also analysed.
\end{abstract}

\section{List of the symbols}

$F_{0} \quad:$ ratio between diffuse solar irradiance and globar solar irradiance (see Eq. (21))

m : air mass

$q_{\mathrm{O}_{3}} \quad$ : ozone vertical load

$s \quad:$ tilt angle of a surface

$t \quad:$ : time

$t_{\mathrm{r}} \quad:$ : time of rise of the sun

$t_{\mathrm{s}} \quad:$ time of set of the sun

$w \quad$ : precipitable water vapour amount

$W_{\mathrm{X}}(\lambda, t)$ : spectral solar irradiance on horizontal surface; $X$ may stand for subscripts B(beam), D(diffuse), G(global) and $\mathrm{T}$ (global on a tilted surface)

$$
\begin{array}{ll}
\bar{W}_{\mathbf{X}}(\lambda) \quad: \bar{W}_{\mathbf{X}}(\lambda)=\int_{t_{\mathbf{r}}}^{t_{\mathbf{s}}} W_{\mathbf{X}}(\lambda, t) \mathrm{d} t \\
W_{\mathbf{X}_{0}} & : W_{\mathbf{X}_{0}}=\int_{0}^{\infty} \bar{W}_{\mathbf{X}}(\lambda) \mathrm{d} \lambda
\end{array}
$$

\begin{tabular}{|c|c|}
\hline $\bar{W}_{\mathbf{w}}^{\mathrm{R}}(\lambda)$ & $\begin{array}{l}\text { : weighted relative spectrum of the global } \\
\text { irradiance (see Eq. (22)) }\end{array}$ \\
\hline$\alpha, \beta$ & : turbidity parameters \\
\hline ? & : solar declination \\
\hline$\phi$ & : terrestrial latitude \\
\hline$\lambda$ & : wavelength \\
\hline$\omega$ & : hourly angle of the sun \\
\hline$\psi$ & $\begin{array}{l}\text { angle between the direction of } t \\
\text { incoming radiation and the normal } \\
\text { the collecting surface }\end{array}$ \\
\hline$\tau_{0}(\lambda)$ & : ozone transmittance \\
\hline$\tau_{\mathrm{g}}(\lambda)$ & : mixed gases transmittance \\
\hline$\tau_{M}(\lambda)$ & : aerosol transmittance \\
\hline$\tau_{\mathbf{R}}(\lambda)$ & $\begin{array}{l}\text { : transmittance due to molecular scatt } \\
\text { ing }\end{array}$ \\
\hline$\tau_{\mathrm{w}}($ & : transmittance due to water vapour \\
\hline
\end{tabular}

$\bar{W}_{\mathbf{X}}^{\mathrm{R}}(\lambda) \quad:$ daily relative spectrum $: \bar{W}_{\mathbf{X}}^{\mathrm{R}}(\lambda)=\frac{\bar{W}_{\mathbf{X}}(\lambda)}{W_{\mathbf{X}_{0}}}$

\section{Introduction.}

Many solar energy applications require a detailed knowledge of the clear sky radiance spectrum. For example knowing the yearly averaged spectrum 
allows the modelling of long term performance of solar heating systems using selective devices [1].

The daily radiance spectrum is the fundamental quantity to know where dealing with natural cooling devices and, in general, with solar systems with active components covered by glass or plastic films [1].

The knowledge of the daily radiance spectrum is also quite relevant for the efficiency modelling of internal storage biological systems and to compute the thermodynamic upper limit to the efficiency of systems with external storage, like photovoltaic systems $[2,3]$.

In all the above mentioned cases the knowledge with some details of the radiance spectrum at the earth surface is important both to model the behaviour of solar systems and to select appropriate materials displaying optimal transmission and absorption characteristics.

There are several models to compute instantaneous clear sky solar radiation. The most detailed models treat the atmosphere as a multi-layered medium [4-6] but require the precise knowledge of a number of meteorologically relevant parameters as, for example, the vertical variation of aerosol concentration and its physical chemical characteristics, the vertical profile of water vapour and ozone, the visual range and so on; in other words parameters which are difficult to estimate with a precision comparable to the quality of the mathematical treatment.

Simplified models require the knowledge of few atmospheric parameters (e.g. turbidity, water vapour and ozone columnal contents) and refer to an equivalent homogeneous atmosphere. Some of these models allow to compute only global values of irradiation [7-12], where other ones give the radiance spectrum and its components, both beam and diffuse [13-16]. All of these simplified models seem to produce results which are in good agreement with the more sophisticated (from the mathematical point of view) ones.

However the use of either class of methods is not straight-forward when applied to modelling of real systems. In many cases only a "mean " radiance spectrum is wanted, not any instantaneous values $[2,3$, $17,18]$. In this case it would be most useful to obtain values on clear sky spectral radiance at a given location with the precision required by the system under examination, using fewest input parameters and a most simplified and fast computing procedure.

This paper presents a methodology to solve the formerly posed problem. The method is validated using Böer's model [13] as a reference, but the results should be independent of this choice.

\section{Basic equations, hypotheses and definitions.}

Böer's model has been modified in order to use recently derived water vapour spectral absorption coefficients and to account for diffuse radiation anisotropy.

The basic equations, in Böer's model, to compute the instantaneous direct and diffuse spectral radiance on a horizontal surface (denoted respectively by $W_{\mathrm{B}}(\lambda, t)$ and $\left.W_{\mathrm{D}}^{\prime}(\lambda, t)\right)$ are

$$
\begin{array}{r}
W_{\mathbf{B}}(\lambda, t)=W_{\text {ex }}(\lambda) \tau_{0}(\lambda) \tau_{\mathbf{w}}(\lambda) \tau_{\mathbf{R}}(\lambda) \tau_{\mathbf{g}}(\lambda) \cos \theta \times \\
\times\left\{\tau_{\mathbf{M}}(\lambda)+f_{\mathbf{M}}^{\prime}\left(1-\tau_{\mathbf{M}}(\lambda)\right)\right\} \\
W_{\mathbf{D}}^{\prime}(\lambda, t)=W_{\text {ex }}(\lambda) \tau_{0}(\lambda) \tau_{\mathbf{w}}(\lambda) \tau_{\mathbf{g}}(\lambda)\left\{\tau_{\mathbf{M}}(\lambda) \times\right. \\
\left.\times f_{\mathbf{R}}\left(1-\tau_{\mathbf{R}}(\lambda)\right)+\tau_{\mathbf{R}}(\lambda) f_{\mathbf{M}}\left(1-\tau_{\mathbf{M}}(\lambda)\right)\right\}
\end{array}
$$

where :

$W_{\text {ex }}(\lambda)$ is the extraatmospheric irradiance corrected for sun-earth distance;

$f_{\mathbf{R}} \quad$ is the portion of radiation diffused in the forward hemisphere by molecular scattering;

$f_{M}^{\prime} \quad$ is the portion of radiation diffused in the forward direction by large particles; $f_{\mathrm{M}}^{\prime}=0.6$;

$f_{\mathrm{M}} \quad$ is the portion of radiation diffused in the forward hemisphere by large particles; $f_{\mathrm{M}}=0.07$

$\theta \quad$ is sun's zenith angle

The transmissivities were computed in our model using the following functions :

a) ozone transmittance

$$
\tau_{0}=\exp \left(-K_{0}(\lambda) m q_{\mathrm{O}_{3}}\right)
$$

where $m$ is relative air mass :

$q_{\mathrm{O}_{3}}$ is ozone vertical load;

$K_{0}^{3}(\lambda)$ are ozone absorption coefficients [19];

b) transmittance due to water vapour

$$
\tau_{\mathrm{w}}(\lambda)=\exp \left(-a(w \cdot m)^{b}\right)
$$

where $w$ is precipitable water vapour amount; $a$ and $b$ are coefficients found by Guzzi et al. [20];

c) aerosol transmittance

$$
\tau_{\mathrm{M}}(\lambda)=\exp \left(-\beta \lambda^{\alpha}\right)
$$

where $\alpha$ and $\beta$ are turbidity parameters [21]; they contain some information on aerosol radiative effects in the visible and near-infrared;

d) transmissivity due to molecular scattering

$$
\tau_{\mathbf{R}}(\lambda)=\exp \left(-0.008735 . \lambda^{-4.08}\right)
$$

following Kondratyev [22];

e) mixed gases transmittance

$$
\tau_{\mathbf{g}}(\lambda)=\exp \left(-\frac{1.41 K_{\mathbf{g}}(\lambda) \cdot m}{1+118.3 K_{\mathbf{g}}(\lambda) \cdot m}\right)
$$

where the coefficients $K_{g}(\lambda)$ are taken from Leckner [14]. 
In order to account for anisotropy of the diffuse radiation due to the higher brightness values near the sun's position, the quantity $W_{\mathrm{D}}^{\prime}(\lambda, t)$ is modified according to Temps and Coulson [23] and Klucker [24] to yield $W_{\mathrm{D}}(\lambda, t)$ :

$$
\begin{aligned}
W_{\mathrm{D}}(\lambda, t)=W_{\mathrm{D}}^{\prime}(\lambda, t) & \times \\
\times & \left\{1+F(\lambda, t) \cos ^{2} \theta \sin ^{3} \theta\right\}
\end{aligned}
$$

where $W_{\mathrm{D}}^{\prime}$ is computed via equation (2) and $F(\lambda, t)$ is defined as :

$$
F(\lambda, t)=1-\left(\frac{W_{\mathrm{D}}^{\prime}(\lambda, t)}{W_{\mathrm{D}}^{\prime}(\lambda, t)+W_{\mathrm{B}}(\lambda, t)}\right)^{2} .
$$

Finally the global radiation instantaneous spectrum $W_{\mathrm{G}}(\lambda, t)$ can be computed using

$$
W_{\mathrm{G}}(\lambda, t)=W_{\mathrm{B}}(\lambda, t)+W_{\mathrm{D}}(\lambda, t) .
$$

Equations (1), (2), (8) and (10) allow the computation of radiation on a horizontal surface. In order to compute the same quantities over a South oriented surface with a tilt angle $s$ the spectrum of global radiation $W_{\mathrm{T}}(\lambda, t)$ can be computed following Liu and Jordan [25], Temps and Coulson [23] and Klucker [24] as :

$$
W_{\mathrm{T}}(\lambda, t)=W_{\mathrm{BT}}(\lambda, t)+W_{\mathrm{DT}}(\lambda, t)
$$

where $W_{\mathrm{BT}}(\lambda, t)$ and $W_{\mathrm{DT}}(\lambda, t)$ refer to direct respectively diffuse radiation on a tilted surface :

$$
\begin{array}{r}
W_{\mathrm{BT}}(\lambda, t)=\left(W_{\mathrm{G}}(\lambda, t)-W_{\mathrm{D}}^{\prime}(\lambda, t)\right) \frac{\cos \psi}{\cos \theta}+\left(W_{\mathrm{G}}(\lambda, t)-W_{\mathrm{D}}^{\prime}(\lambda, t)\right) \frac{\rho\left(1-\cos ^{2} \frac{s}{2}\right)\left(1+\sin ^{2} \frac{\theta}{2}\right)}{\cos \theta} \\
W_{\mathrm{DT}}(\lambda, t)=W_{\mathrm{D}}^{\prime}(\lambda, t) \cdot\left(\frac{1+\cos s}{2}\right) \cdot\left(1+F(\lambda, t) \sin ^{3} \frac{s}{2}\right) \cdot\left(1+F(\lambda, t) \cos ^{2} \psi \sin ^{3} \theta\right)+ \\
+W_{\mathrm{D}}^{\prime}(\lambda, t) \cdot \rho\left(1-\cos ^{2} \frac{s}{2}\right) \cdot\left(1+\sin ^{2} \frac{\theta}{2}\right)
\end{array}
$$

where $\psi$ is the angle between the direction of the incoming radiation and the normal to the surface.

Using this approximation and equations (1) through (13) the daily spectrum of radiation $\bar{W}_{\mathbf{X}}(\lambda)$ can be computed as :

$$
\bar{W}_{\mathbf{X}}(\lambda)=\int_{t_{\mathbf{r}}}^{t_{\mathbf{s}}} W_{\mathbf{X}}(\lambda, t) \mathrm{d} t
$$

where $\mathrm{X}$ may stand for the subscripts $\mathrm{B}$ (beam), $\mathrm{D}$ (diffuse) and $\mathrm{G}$ (global);

$t_{\mathrm{r}}$ and $t_{\mathrm{s}}$ are respectively the time of rise and set of the sun.

The daily relative spectrum $\bar{W}_{\mathbf{X}}^{\mathrm{R}}(\lambda)$ can be defined as :

$$
\bar{W}_{\mathbf{X}}^{\mathbf{R}}(\lambda)=\frac{\bar{W}_{\mathbf{X}}(\lambda)}{W_{\mathbf{x}_{\mathbf{0}}}}
$$

with

$$
W_{\mathbf{x}_{0}}=\int_{0}^{\infty} \bar{W}_{\mathbf{x}}(\lambda) \mathrm{d} \lambda
$$

Clear sky spectrum over a surface generally tilted changes mainly for four reasons :

a) changing relative air mass ;

b) variation in atmospheric parameters, in particular of the turbidity parameters and water vapour and ozone vertical loads;

c) changing of the position of the sun relative to the surface; d) besides long term behaviour we must also take into account short term fluctuations on microclimatic scale of the atmospheric content of absorbing and scattering gases and molecules.

Regarding to effect b) we have considered the seasonal behaviour of atmospheric content of water vapour, $\mathrm{O}_{3}$ and turbidity using data of references [19, $21,26]$ (see Table I for values typical in Italy).

Effects due to a) and b) affect both the absolute number of incident photons (i.e. the absolute value of incident radiation) and the shape of the spectrum.

Attention to relative spectra gives evidence to the change of shape. They certainly vary for the same physical mechanism which produces variation in the absolute spectra, but are expected to show variation of smaller amplitude; where this true $\bar{W}_{\mathbf{X}}^{\mathrm{R}}(\lambda)$ could be used to compute $\bar{W}_{\mathrm{X}}(\lambda)$ by using equation (15) once the integral quantity $W_{\mathbf{x}_{0}}$ is measured or estimated using statistical models [27, 28] and/or the correlation with other meteorological parameters [29].

In the paragraphs that follow the seasonal variation of $\bar{W}_{\mathbf{X}}^{\mathrm{R}}(\lambda)$ will be investigated as well as the effects induced by large changes in $\alpha, \beta, q_{\mathrm{o}_{3}}$ and $w$.

\section{Spectra over horizontal surfaces.}

The cumulative spectra of relative global, direct and diffuse radiation (respectively $\bar{W}_{\mathrm{G}}^{\mathrm{R}}(\lambda), \bar{W}_{\mathbf{B}}^{\mathrm{R}}(\lambda)$ and $\left.\bar{W}_{\mathrm{D}}^{\mathrm{R}}(\lambda)\right)$ are plotted in figures $1 \mathrm{a}, 1 \mathrm{~b}$ and $1 \mathrm{c}$. These functions were computed using equations (1) 
Table I. - Mean values of turbidity parameters ( $\alpha$ and $\beta)$, ozone vertical load $\left(q_{\mathrm{O}_{3}}\right)$ and precipitable water vapour amount $(w)$ assumed in our analysis.

\begin{tabular}{|l|c|c|c|c|}
\hline & $\alpha$ & $\beta$ & $w(\mathrm{~cm})$ & $q_{\mathrm{O}_{3}}(\mathrm{~cm})$ \\
\hline January & 1.3 & 0.06 & 0.35 & 1.69 \\
\hline February & 1.3 & 0.08 & 0.36 & 1.67 \\
\hline March & 1.3 & 0.10 & 0.37 & 1.86 \\
\hline April & 1.3 & 0.12 & 0.38 & 2.23 \\
\hline May & 1.3 & 0.12 & 0.38 & 2.66 \\
\hline June & 1.3 & 0.11 & 0.37 & 3.06 \\
\hline July & 1.3 & 0.10 & 0.35 & 3.30 \\
\hline August & 1.3 & 0.08 & 0.34 & 3.33 \\
\hline September & 1.3 & 0.06 & 0.33 & 3.13 \\
\hline October & 1.3 & 0.04 & 0.32 & 2.77 \\
\hline November & 1.3 & 0.04 & 0.32 & 2.33 \\
\hline December & 1.3 & 0.05 & 0.33 & 1.94 \\
\hline
\end{tabular}

through (10), (14) and (15) and the values for $\alpha, \beta, q_{\mathrm{o}_{3}}$ and $w$ shown in table I.

Since the variation of the (cumulative) spectra are rather small, it is possible to represent them by averaged spectra. In the case of global radiation $\bar{W}_{G}^{R}(\lambda)$, for example, the averaged value $\left\langle\bar{W}_{\mathbf{G}}^{\mathrm{R}}(\lambda)\right\rangle$ can be defined as

$$
\left\langle\bar{W}_{\mathrm{G}}^{\mathrm{R}}(\lambda)\right\rangle=\frac{1}{12} \sum_{i=1}^{12} \bar{W}_{\mathrm{G}, i}^{\mathrm{R}}(\lambda)
$$

where $\bar{W}_{\mathbf{G}, i}^{\mathbf{R}}(\lambda)$ is the daily relative spectrum of radiation computed for the $i$-th month of the year.

In figure $2\left\langle\bar{W}_{\mathrm{G}}^{\mathrm{R}}(\lambda)\right\rangle$ is plotted.

The quantity

$$
\bar{\sigma}_{\mathrm{G}}(\lambda)=\sqrt{\frac{\sum_{i=1}^{12}\left(\bar{W}_{\mathrm{G}, i}^{\mathrm{R}}(\lambda)-\left\langle W_{\mathrm{G}}^{\mathrm{R}}(\lambda)\right\rangle\right)^{2}}{12}}
$$

is a measure of how well the single spectra are estimated by $\left\langle W_{G}^{R}(\lambda)\right\rangle$. The quantity $\bar{\sigma}_{\mathrm{G}}(\lambda)$ is plotted in figure 3 as a function of $\lambda$ wavelength. The maximum value found is 0.14 at the region of the spectrum energetically significative, which corresponds to a percentage value of $20 \%$.

The quantity

$$
S_{i}^{1}=\sqrt{\int_{0}^{\infty}\left(\bar{W}_{\mathrm{G}, i}^{\mathrm{R}}(\lambda)-\left\langle W_{\mathrm{G}}^{\mathrm{R}}(\lambda)\right\rangle\right)^{2} \mathrm{~d} \lambda}
$$

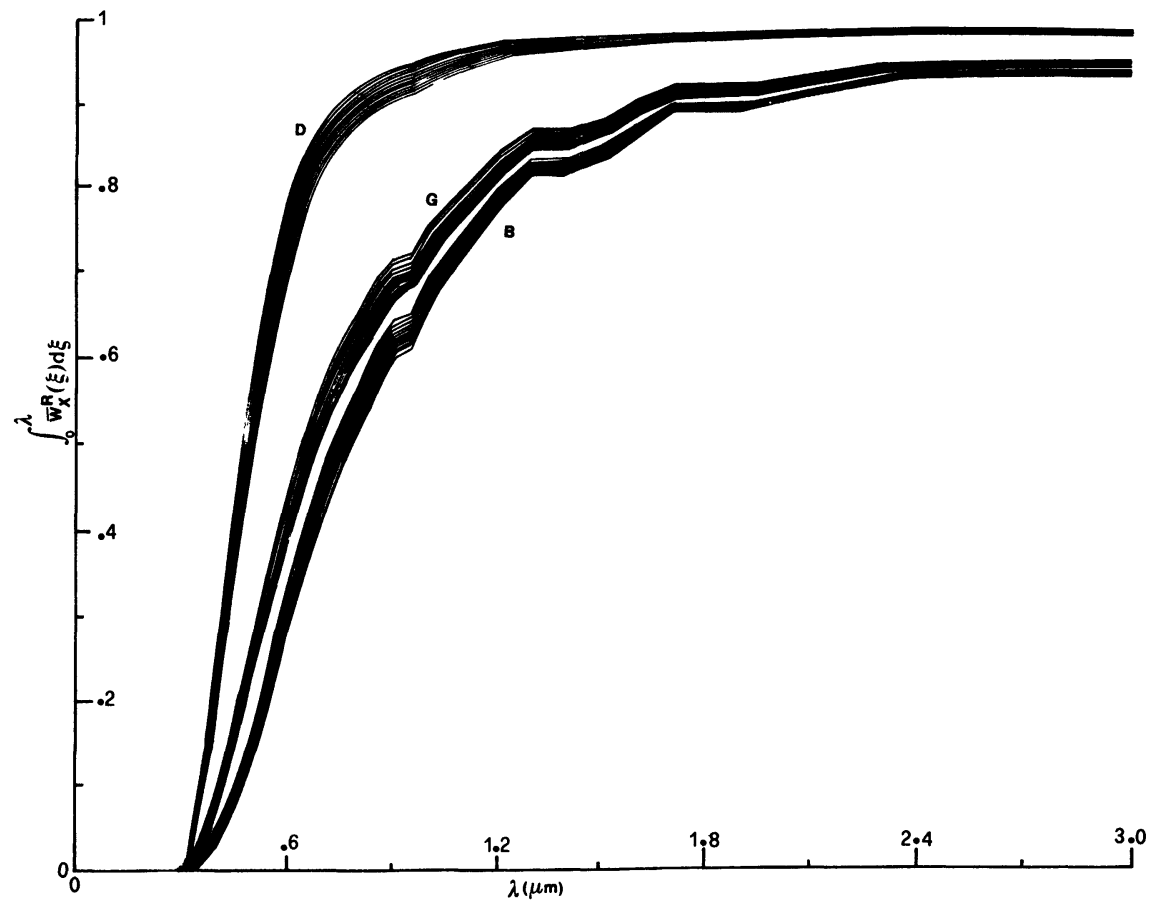

Fig. 1. - Daily relative cumulative spectra for the twelve months of the year : D : diffuse radiation; $G$ : global radiation; B : beam radiation. 


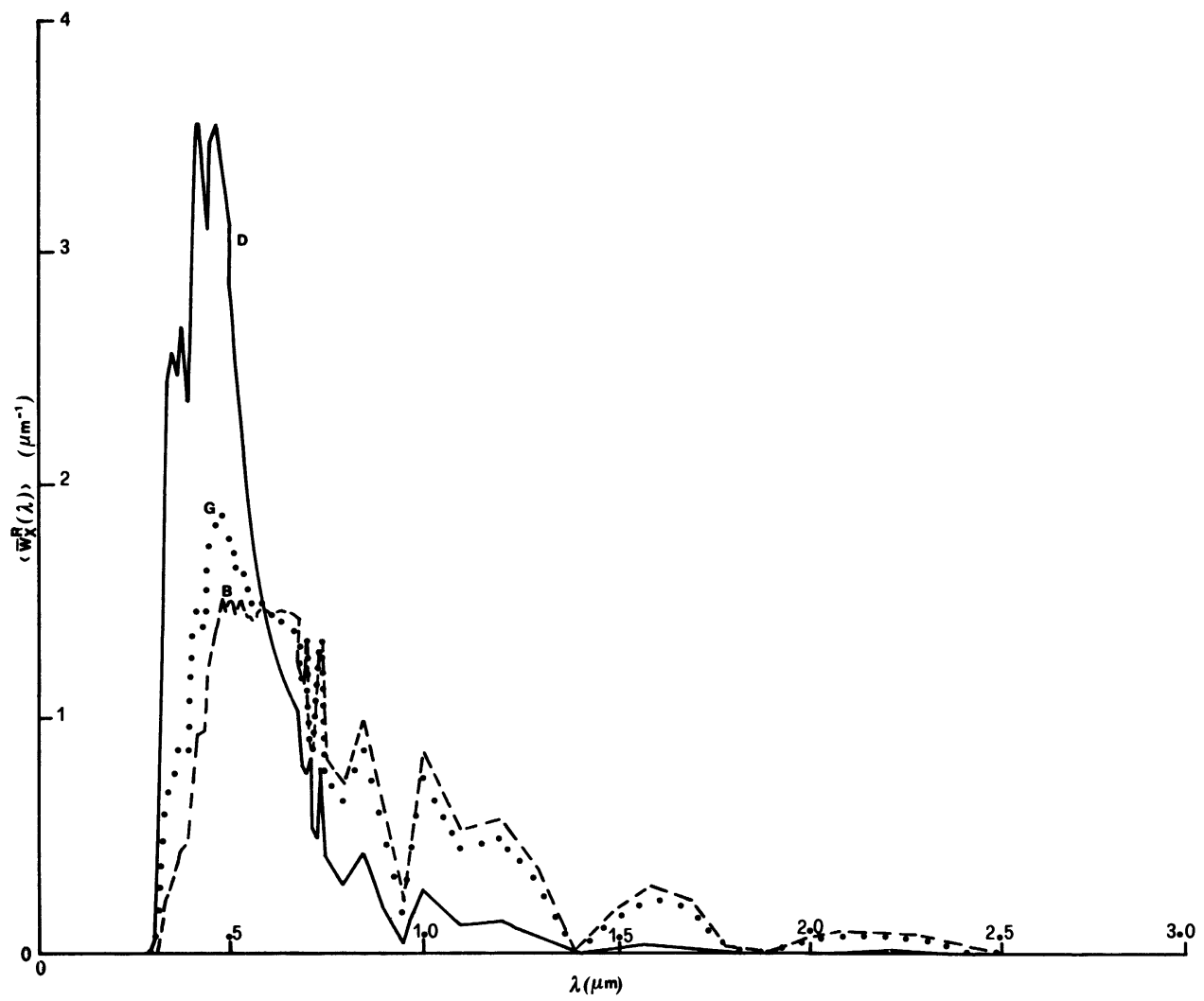

Fig. 2. - Daily average relative spectra : D : diffuse radiation; B : beam radiation; $\mathrm{G}$ : global radiation.

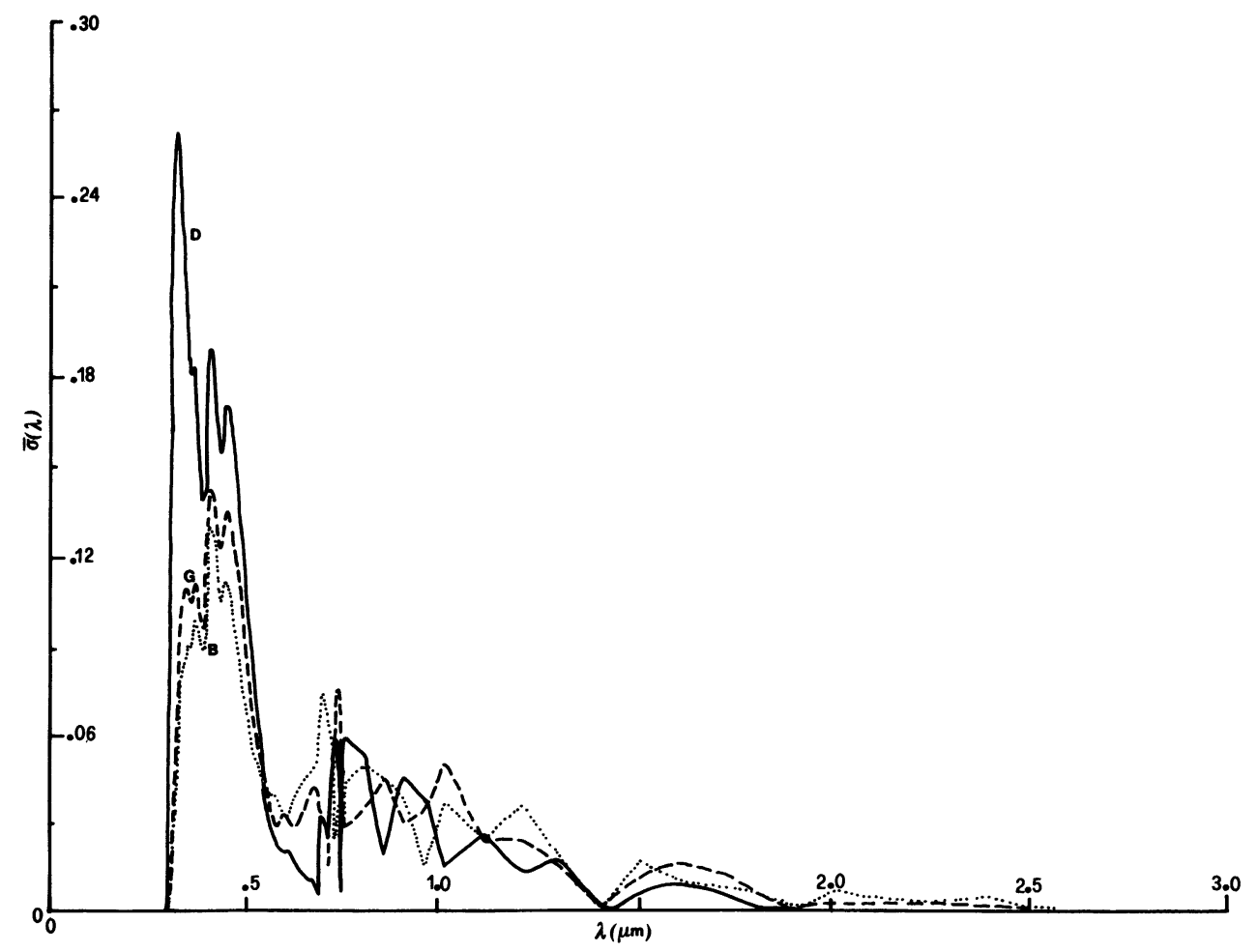

Fig. 3. - Plot $\bar{\sigma} v s . \lambda$ for diffuse radiation (D), beam radiation (B) and global radiation (G). 
can be interpreted as the integrated (over the wavelength spectrum) percentage deviation (the quantities $\bar{W}_{\mathbf{X}}^{\mathrm{R}}(\lambda)$ are relative numbers) which is to be expected when daily relative spectra are estimated by the yearly averaged values. The subscript $i$ runs from 1 to 12 and denotes the month of the year. The $S_{i}^{1}$ values computed for each month are shown in table II. It can be seen that the deviation never exceeds $9 \%$.

Therefore the absolute daily irradiance spectra can be estimated, within the limitation formerly established, by using the plot given in figure 2 and the value of global solar radiation measured at the ground over a horizontal surface $W_{\mathrm{G}_{0}}$, that is

$$
\bar{W}_{\mathrm{G}}(\lambda)=W_{\mathrm{G}_{0}}\left\langle\bar{W}_{\mathrm{G}}^{\mathrm{R}}(\lambda)\right\rangle \text {. }
$$

Table II. - Computed values of $S^{1}$ for each month of the year.

\begin{tabular}{|lc|}
\multicolumn{1}{l}{} & \multicolumn{1}{l}{$\boldsymbol{S}^{1}(\%)$} \\
\hline January & 2.5 \\
\hline February & 3.7 \\
\hline March & 5.8 \\
\hline April & 6.3 \\
\hline May & 5.8 \\
\hline June & 4.8 \\
\hline July & 3.4 \\
\hline August & 1.7 \\
\hline September & 2.6 \\
\hline October & 6.5 \\
\hline November & 10.3 \\
\hline December & 8.9 \\
\hline Mean & 8.8 \\
\hline
\end{tabular}

\section{The method of weighted averages.}

It has been pointed out that the variation of clear sky daily relative spectra is due mainly to the variation of air mass and of the atmospheric parameters $\alpha, \beta, q_{\mathrm{O}_{3}}$ and $w$. The estimation of $\bar{W}_{\mathrm{G}}(\lambda)$ given by equation (20) can be bettered by taking into account these effects.

However one of the main causes which make average daily relative spectra of global radiation to vary during the year is the fact that the relative weight of direct and diffuse radiation varies during the year

because of effects a) and b) discussed in section 2. In order to take into account this effect, we have defined separately direct and diffuse spectra.

To this purpose we introduce explicitely the ratio of direct and diffuse daily radiation to global daily radiation :

$$
\begin{aligned}
& \frac{\int_{0}^{\infty} \bar{W}_{\mathrm{D}}(\lambda) \mathrm{d} \lambda}{W_{\mathrm{G}_{0}}}=\frac{\int_{t_{\mathrm{r}}}^{t_{\mathrm{s}}} \mathrm{d} t \int_{0}^{\infty} \mathrm{d} \lambda W_{\mathrm{D}}(\lambda, t)}{\int_{t_{\mathrm{s}}}^{t_{\mathrm{s}}} \mathrm{d} t \int_{0}^{\infty} \mathrm{d} \lambda W_{\mathrm{G}}(\lambda, t)}=F_{0} \\
& \frac{\int_{0}^{\infty} \bar{W}_{\mathrm{B}}(\lambda) \mathrm{d} \lambda}{W_{\mathrm{G}_{0}}}=\frac{\int_{t_{\mathrm{r}}}^{t_{\mathrm{s}}} \mathrm{d} t \int_{0}^{\infty} \mathrm{d} \lambda W_{\mathrm{B}}(\lambda, t)}{\int_{t_{\mathrm{r}}}^{t_{\mathrm{s}}} \mathrm{d} t \int_{0}^{\infty} \mathrm{d} \lambda W_{\mathrm{G}}(\lambda, t)}=1-F_{0}
\end{aligned}
$$

$F_{0}$ can be easily computed for each month (or for each day) by equations (12) and (13). In many cases they are experimental values measured using standard shadow ring pyranometers. Typical values of $F_{0}$ for temperate climates are given in table III.

In strict analogy with the method adopted to define $\bar{W}_{\mathrm{G}}^{\mathrm{R}}(\lambda)$ (see Eq. (15)) the relative yearly mean of diffuse and direct irradiance spectra, respectively $\left\langle\bar{W}_{\mathrm{D}}^{\mathrm{R}}(\lambda)\right\rangle$ and $\left\langle\bar{W}_{\mathrm{B}}^{\mathrm{R}}(\lambda)\right\rangle$, can be defined. They are plotted in figure 2 also.

Table III. - Typical values of $F_{0}$ (ratio between daily diffuse solar radiation and daily global solar radiation) for Italy as a function of the month.

\begin{tabular}{|ll|}
\multicolumn{1}{l}{} & $F_{0}$ \\
\hline January & 0.283 \\
\hline February & 0.206 \\
\hline March & 0.157 \\
\hline April & 0.129 \\
\hline May & 0.118 \\
\hline June & 0.116 \\
\hline July & 0.122 \\
\hline August & 0.140 \\
\hline September & 0.178 \\
\hline October & 0.239 \\
\hline November & 0.315 \\
\hline December & 0.340 \\
\hline
\end{tabular}


In analogy with equation (18), the spectral quantities $\bar{\sigma}_{\mathrm{D}}(\lambda)$ and $\bar{\sigma}_{\mathrm{B}}(\lambda)$ can be computed and are reported in figure 3. The maximum values of $\bar{\sigma}_{\mathrm{D}}(\lambda)$ and $\bar{\sigma}_{\mathrm{B}}(\lambda)$ are 0.27 and 0.13 respectively and the percentage deviations in the spectral regions where most of the energy is to be found are respectively of the order of $20 \%$ and $10 \%$.

Finally the daily relative spectra of global radiation $\bar{W}_{\mathrm{w}}^{\mathrm{R}}(\lambda)$ can be computed (for each month) according to

$$
\bar{W}_{\mathrm{w}}^{\mathrm{R}}(\lambda)=F_{0}\left\langle\bar{W}_{\mathrm{D}}^{\mathrm{R}}(\lambda)\right\rangle+\left(1-F_{0}\right)\left\langle\bar{W}_{\mathbf{B}}^{\mathrm{R}}(\lambda)\right\rangle .
$$

When the appropriate values of $F_{0}$ are used for each month of the year, then the quantity $\bar{W}_{\mathrm{w}}^{\mathrm{R}}(\lambda)$ can be compared to the spectra $\bar{W}_{\mathrm{G}}^{\mathrm{R}}(\lambda)$ obtained using the model.

In analogy with equation (19) a global percentage error $S_{i}^{2}$ (cumulative over the whole wavelength spectrum) can be defined which is a measure of the difference between $\bar{W}_{\mathrm{G}}^{\mathrm{R}}(\lambda)$ and $\bar{W}_{\mathrm{w}}^{\mathrm{R}}(\lambda)$. The twelve numbers $S_{i}^{2}$ are reported in table IV. The maximum and average percentage errors are about 6.7 and 4 per cent respectively.

Therefore, for any selected month of the year, the absolute daily spectrum of global irradiance $\bar{W}_{\mathrm{G}}(\lambda)$ can be computed using the relation

$$
\bar{W}_{\mathrm{G}}(\lambda)=W_{\mathrm{G}_{0}} \bar{W}_{\mathrm{w}}^{\mathrm{R}}(\lambda) .
$$

Table IV. - Computed values of $S^{2}$ for each month of the year.

$$
S^{2}(\%)
$$

\begin{tabular}{|ll|}
\hline January & 6.7 \\
\hline February & 4.2 \\
\hline March & 2.7 \\
\hline April & 2.6 \\
\hline May & 3.2 \\
\hline June & 4.0 \\
\hline July & 4.8 \\
\hline August & 5.2 \\
\hline September & 4.6 \\
\hline October & 3.1 \\
\hline November & 3.3 \\
\hline December & 6.5 \\
\hline Mean & 4.2 \\
\hline
\end{tabular}

Comparing this technique to the former which uses the curve $\left\langle W_{G}^{R}(\lambda)\right\rangle$ (reported in Fig. 2) and equation (20), in this case more information are needed to compute the daily spectrum $\bar{W}_{\mathrm{G}}(\lambda)$ that is two curves, $\left\langle\bar{W}_{\mathbf{D}}^{\mathbf{R}}(\lambda)\right\rangle$ and $\left\langle\bar{W}_{\mathbf{B}}^{\mathrm{R}}(\lambda)\right\rangle$, as a function of wavelength (also plotted in Fig. 2) and the appropriate value of $\boldsymbol{F}_{0}$. However the second method allows the computation of daily spectrum of global irradiance with an accuracy which is sufficient for solving a large variety of design of solar systems.

\section{Instantaneous spectra on horizontal surfaces.}

The two proposed methods permit the computation of the relative and absolute spectra of daily global irradiance reaching the ground without computing the spectrum itself, that is with no regard to the actual mechanisms of absorption and scattering of radiation. For some applications when modelling photovoltaic systems, a better resolution is needed. The usual procedure is to estimate the daily spectrum by the instantaneous values computed for fixed values of air mass (as, for example, $m=1, m=1.2, m=2$ and so on). This technique is usually fast since it does not involve a time integration of the single spectra computed using a model similar to the one presented in this paper. However such a technique can lead to erroneous results since the instantaneous spectrum varies strongly during the course of the day mainly because of the variation in relative air mass. As an example, in figures $4 \mathrm{a}, 4 \mathrm{~b}$ and $4 \mathrm{c}$ the deviations, $\delta(\lambda)$, of the instantaneous relative spectra $\left(W_{\mathrm{X}}^{\mathrm{R}}(m, \lambda)\right)$ computed at an assigned air mass $m$ from the daily relative $\left(\bar{W}_{\mathrm{X}}^{\mathrm{R}}(\lambda)\right)$ corresponding to a typical summer day are reported. The deviation $\delta(\lambda)$ is computed as :

$$
\delta(\lambda)=\bar{W}_{\mathbf{X}}^{\mathrm{R}}(\lambda)-W_{\mathbf{X}}^{\mathbf{R}}(m, \lambda) .
$$

A value of air mass must be chosen in order to obtain a good approximation of the daily spectrum. A value of effective air mass $m^{*}$ can be defined :

$$
m^{*}=-\ln \frac{\int_{t_{\mathrm{r}}}^{t_{\mathrm{s}}} \exp (-m(t)) \cos \theta \mathrm{d} t}{\int_{t_{\mathrm{r}}}^{t_{\mathrm{s}}} \cos \theta \mathrm{d} t} .
$$

The latter formula takes into account the functional relationship between radiance and air mass ( $m$ appears as an argument in the transmittance function). Moreover the presence of the $\cos \theta$ term allows to optimize the energy reaching an horizontal surface. Since $\exp (-m(t))$ is the transmittance for an atmosphere of mean optical depth (over the whole spectrum), the derived value of $m^{*}$ will produce best results with atmospheres characterized by high values of extinction optical depth. 


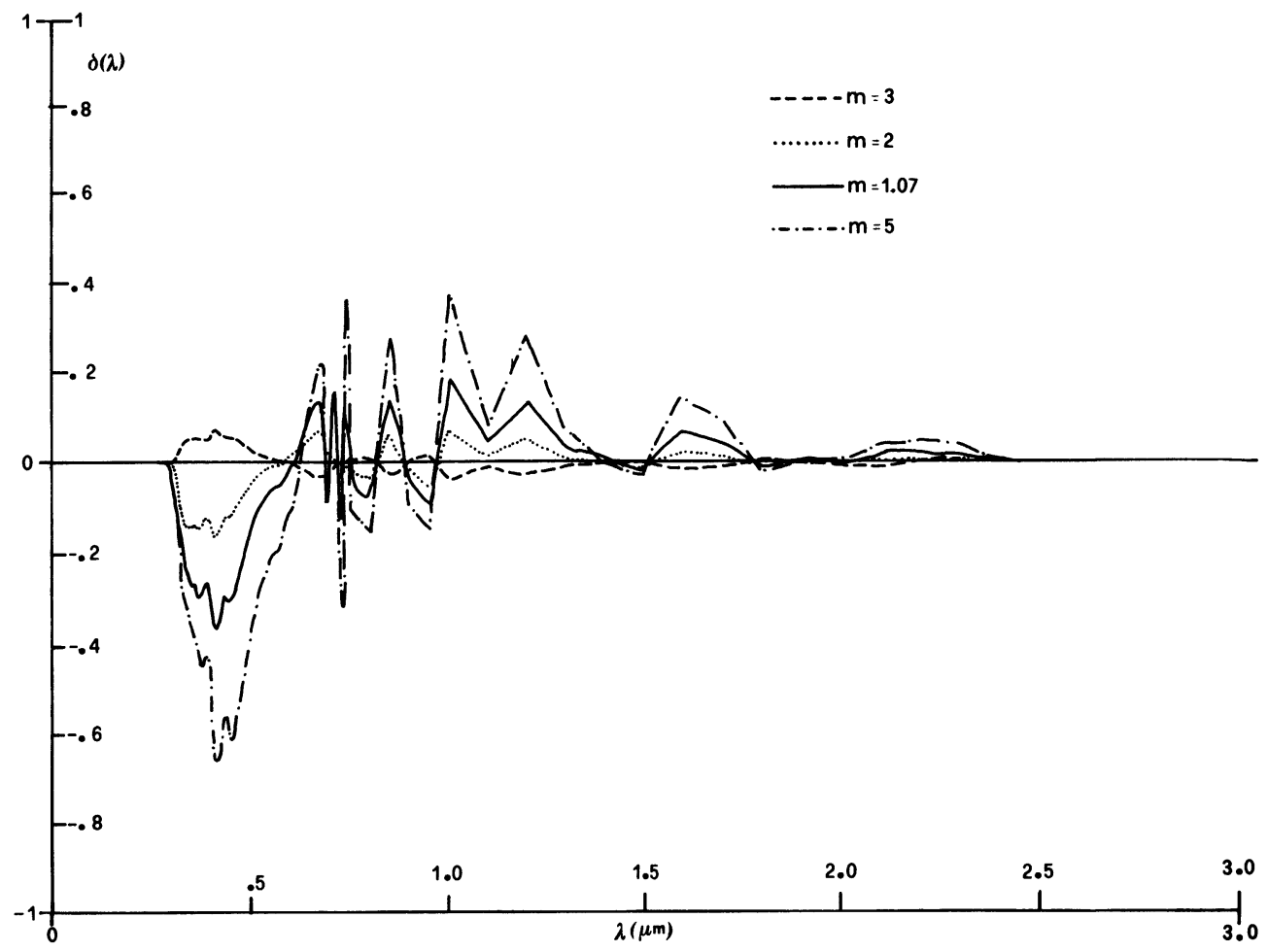

Fig. 4a. - Deviations, $\delta(\lambda)$, of the instantaneous relative spectra of global radiation at different air masses $(m)$ from the daily relative spectrum corresponding to a typical summer day.

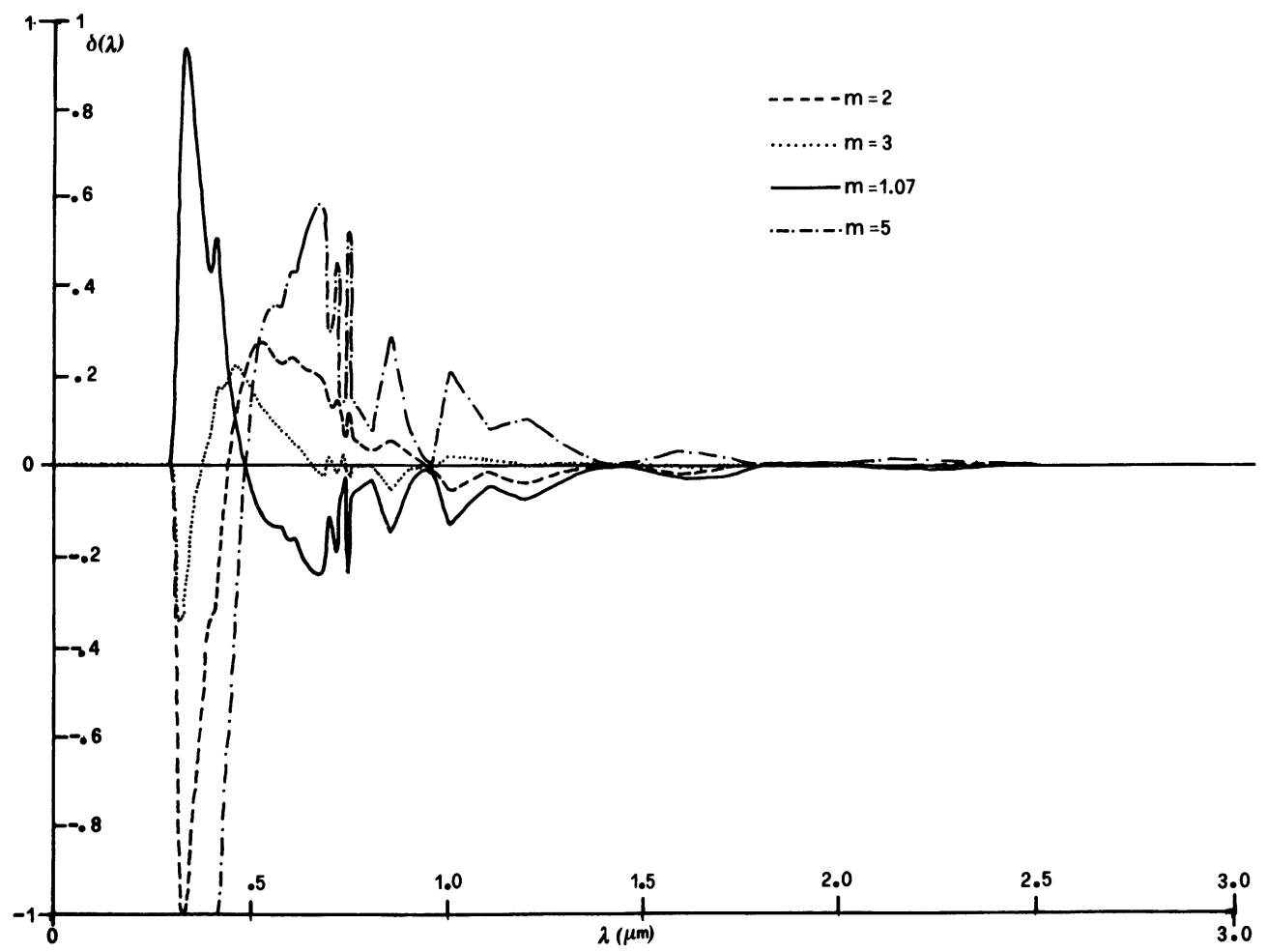

Fig. 4b. - As figure $4 a$ but for diffuse radiation. 


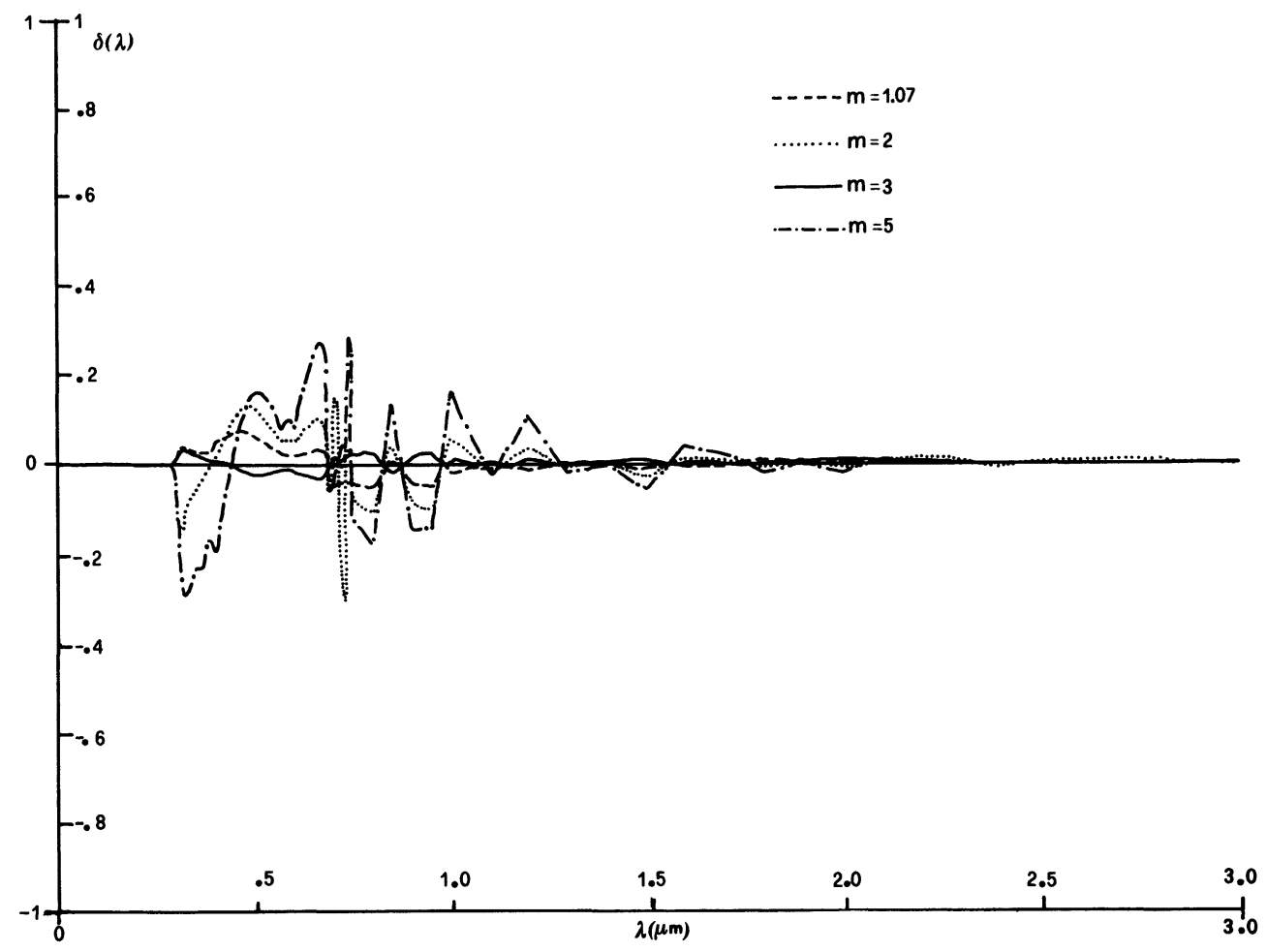

Fig. 4c. - As figure 4a but for beam radiation.

Since

$$
\cos \theta=\sin \delta \sin \phi+\cos \delta \cos \phi \cos \omega
$$

where $\delta$ is solar declination;

$\phi$ is the latitude;

$\omega$ is hourly angle, $\omega=\frac{2 \pi}{24}(t-12)$

and the relative air mass can be computed with high degree of accuracy as [30]

$$
m=\left(\cos \theta+\frac{9.4 \times 10^{-4}}{(1.639-\theta)^{1.253}}\right)^{-1}
$$

the value of $m^{*}$ can be easily computed.

For any given time of the year six spectra were computed (corresponding to $m=1,2,3,4, m^{+}$and $m^{*}$, where $m^{+}$is the air mass at solar noon). They have been compared with the correct relative spectra calculated using equation (15).

In analogy with equation (19), a measure of the mean error which results in estimating $\bar{W}_{\mathbf{X}}^{\mathrm{R}}(\lambda)$ by the six spectra $W_{\mathbf{X}}^{\mathrm{R}}(\lambda, m)$ can be computed. This numbers, which will be referred to as $T^{1}, T^{2}, T^{3}, T^{4}$, $T^{+}$and $T^{*}$, are shown in table $\mathrm{V}$.

The irradiance spectrum computed for $m=m^{*}$ is in all cases the best estimate of the relative daily spectrum and $T^{*}$ is about one third $(1.5 \%$ on the average against $4.2 \%$ ) of the error obtained when using the method outlined in section 4 .

Table V. - Computed values of $\mathrm{m}^{*}$ and $\mathrm{m}^{+}$for the months corresponding to the solstices and equinoxes. For the same months a measure $(T)$ of the mean error which results in estimating $\bar{W}_{\mathbf{X}}^{\mathrm{R}}(\lambda)$ by the six spectra $W_{\mathbf{X}}^{\mathrm{R}}(\lambda, m)$ is shown for each considered value of $m\left(m=1,2,3,4, m^{+}, m^{*}\right)$.

\begin{tabular}{|l|c|c|c|c|c|c|c|c|}
\cline { 3 - 9 } \multicolumn{1}{c|}{} & \multicolumn{1}{c|}{} & \multicolumn{7}{c|}{$T(\%)$} \\
\cline { 2 - 10 } \multicolumn{1}{c|}{} & $m^{+}$ & $m^{*}$ & $m=1$ & $m=2$ & $m=3$ & $m=4$ & $m=m^{+}$ & $m=m^{*}$ \\
\hline March & 1.37 & 2.08 & 4.2 & 1.6 & 4.7 & 7.6 & 2.3 & 1.3 \\
\hline June & 1.06 & 1.68 & 2.9 & 3.2 & 7.2 & 10.7 & 2.5 & 1.3 \\
\hline September & 1.37 & 2.08 & 7.1 & 0.8 & 6.6 & 11.5 & 3.9 & 1.4 \\
\hline December & 2.27 & 3.67 & 15.6 & 8.2 & 2.1 & 3.6 & 4.9 & 2.1 \\
\hline
\end{tabular}




\section{Tilted surfaces.}

The three methods outlined in sections 3,4 and 5 allow to compute the relative daily spectra (and hence the absolute spectra) with varying accuracy. The methods were applied to horizontal surfaces, while systems which convert solar energy make use of acceptance surfaces which are inclined to maximize energy conversion.

The relative daily spectra of global radiation over surfaces southward sloping by an angle $s, \bar{W}_{\mathrm{T}}^{\mathrm{R}}(\lambda ; s)$, can be estimated by a quantity $W_{\mathrm{T}}^{\mathrm{R}}(\lambda, s)$ for any month of the year. In analogy with equations 15, 22 and $24 W_{\mathrm{T}}^{\mathrm{R}}(\lambda, s)$ can be computed by the following three methods :

1. $W_{\mathbf{T}}^{\mathbf{R}}(\lambda, s)=\frac{1}{12} \sum_{i=1}^{12} \bar{W}_{\mathrm{T}, i}^{\mathbf{R}}(\lambda ; s)$

2. $W_{\mathrm{T}}^{\mathrm{R}}(\lambda, s)=F_{0}\left\langle\bar{W}_{\mathrm{DT}}^{\mathrm{R}}(\lambda ; s)\right\rangle+\left(1-F_{0}\right)$

3. $W_{\mathrm{T}}^{\mathrm{R}}(\lambda, s)=\frac{W_{\mathrm{T}}\left(\lambda, m^{*} ; s\right)}{\int_{0}^{\infty} W_{\mathrm{T}}\left(\lambda, m^{*} ; s\right) \mathrm{d} \lambda}$.

$$
\times\left\langle\bar{W}_{\mathrm{BT}}^{\mathrm{R}}(\lambda ; s)\right\rangle
$$

In order to compute the quantities $W_{\mathrm{T}}^{\mathrm{R}}(\lambda, s)$ equations (11), (12) and (13) take place respectively of equations (10), (1) and (8), which are valid for horizontal surfaces.

A comparison of the quality of the three methods is shown in table VI. The quantity shown is $S_{\mathrm{T}}$, which is computed in analogy with equation (19). The computations are done for the solstices and equinoxes and for various inclinations (the orientation of the surface being southward in all cases). The results show that the three methods are reliable also when dealing with inclined surfaces.

The computation of the daily absolute spectra once the relative one is known is immediate. All is needed is to multiply $\widetilde{W}_{\mathrm{T}}^{\mathrm{R}}(\lambda, s)$ by the corresponding global radiation value for the month under examination, which can be a climatological value or a mean value obtained from experimental data.

\section{Influence of atmospheric parameters.}

In the preceding sections three approximated methods were shown to estimate the spectra of daily solar irradiance in clear sky mean climatic conditions. However, as it has already been pointed out, atmospheric parameters may undergo rather large fluctuations around their mean values.

In this section the three methods will be tested for values of parameters $\alpha, \beta, q_{\mathrm{O}_{3}}$ and $w$ which differ from their mean values.

Following Böer [13] five meteorological typical conditions were selected. The values of the parameters, for each meteorological condition is shown in table VII.

Using the three procedures outlined in the sections 3 , 4 and 5 (horizontal surface) the global error $S_{\mathrm{B}}$ is computed, in analogy with equation (19), i.e.

$$
S_{\mathbf{B}}=\sqrt{\int_{0}^{\infty}\left(\bar{W}_{\mathbf{G}, i}^{\mathrm{R}}(\lambda)-\widetilde{W}_{\mathbf{G}}^{\mathrm{R}}(\lambda)^{2} \mathrm{~d} \lambda .\right.}
$$

where $\widetilde{W}_{\mathrm{G}}^{\mathrm{R}}(\lambda)$ is the estimated spectral daily solar irradiance using anyone of the proposed method.

The values of $S_{\mathbf{B}}$ are also shown in table VII.

Rather extreme variations of atmospheric parameters cause an average error of $6 \%$ (methods 1 and 2 )

Table VI. - Computed values of $S_{\mathrm{T}}$ at the solstices and equinoxes for various slopes. The heading numbers 1,2

\begin{tabular}{|c|c|c|c|c|c|c|c|c|c|c|c|c|c|c|c|}
\hline & \multicolumn{15}{|c|}{$S_{\mathrm{T}}(\%)$} \\
\hline & \multicolumn{3}{|c|}{ March } & \multicolumn{3}{|c|}{ June } & \multicolumn{3}{|c|}{ September } & \multicolumn{3}{|c|}{ December } & \multicolumn{3}{|c|}{ Mean } \\
\hline & 1 & 2 & 3 & 1 & 2 & 3 & 1 & 2 & 3 & 1 & 2 & 3 & 1 & 2 & 3 \\
\hline $15^{\circ} S$ & 7.5 & 2.7 & 1.3 & 4.5 & 4.7 & 0.6 & 1.6 & 4.5 & 1.0 & 4.7 & 8.3 & 1.8 & 4.6 & 5.0 & 1.2 \\
\hline $30^{\circ} S$ & 8.6 & 2.7 & 1.4 & 4.2 & 5.0 & 0.5 & 2.5 & 4.3 & 0.9 & 9.7 & 10.0 & 2.8 & 6.2 & 5.5 & 1.4 \\
\hline $45^{\circ} S$ & 9.5 & 2.6 & 1.5 & 3.7 & 5.0 & 0.5 & 3.5 & 4.2 & 0.9 & 12.9 & 10.4 & 3.5 & 7.4 & 5.5 & 1.6 \\
\hline $60^{\circ} S$ & 10.1 & 2.7 & 1.6 & 3.0 & 4.7 & 0.5 & 4.4 & 4.0 & 0.9 & 15.3 & 11.1 & 4.1 & 8.2 & 5.6 & 1.8 \\
\hline $75^{\circ} S$ & 10.6 & 2.7 & 1.9 & 1.9 & 3.9 & 1.0 & 5.0 & 3.8 & 1.1 & 17.3 & 11.6 & 4.6 & 8.7 & 5.5 & 2.1 \\
\hline $90^{\circ} S$ & 10.9 & 2.8 & 2.1 & 1.8 & 2.5 & 3.5 & 5.3 & 3.5 & 1.4 & 19.0 & 11.9 & 5.0 & 9.2 & 5.2 & 3.0 \\
\hline
\end{tabular}
and 3 refer to the three methods proposed to calculate $\widetilde{W}_{\mathrm{T}}^{\mathrm{R}}(\lambda, s)$. 
Table VII. - Selected parameters $\alpha, \beta, q_{\mathrm{O}_{3}}$ and $w$ for the sensitivity analysis and corresponding results $\left(S_{\mathrm{B}}\right.$ values). As in table VI, the heading numbers 1,2 and 3 refer to the three methods proposed to calculate $\widetilde{W}_{\mathrm{G}}^{\mathrm{R}}(\lambda)$.

\begin{tabular}{|c|c|c|c|c|c|c|c|}
\cline { 3 - 8 } \multicolumn{1}{c|}{} & \multicolumn{4}{c|}{} & \multicolumn{3}{c|}{$S_{\mathrm{B}}(\%)$} \\
\hline & $\cdot \alpha$ & $\beta$ & $q_{\mathrm{O}_{3}}(\mathrm{~cm})$ & $w(\mathrm{~cm})$ & 1 & 2 & 3 \\
\hline$a$ & 1.5 & 0.03 & 0.34 & 0.4 & 10.4 & 11.3 & 2.4 \\
\hline$b$ & 1.3 & 0.06 & 0.25 & 1.0 & 6.6 & 6.1 & 0.9 \\
\hline$c$ & 1.1 & 0.09 & 0.34 & 1.5 & 6.7 & 6.4 & 0.7 \\
\hline$d$ & 0.6 & 0.25 & 0.34 & 4.5 & 4.4 & 4.8 & 1.4 \\
\hline$e$ & 0.8 & 0.15 & 0.44 & 3.0 & 2.2 & 1.7 & 1.1 \\
\hline
\end{tabular}

and $1.3 \%$ (third method). Since the fluctuations in parameters used for the study are rather extreme, it can be said that the three proposed methods are able to estimate the spectrum of daily global solar irradiance in most clear sky conditions with the same accuracy as when dealing with average atmospheric conditions.

\section{Conclusions.}

Relative spectra of clear sky daily solar global radiation are an important quantity to computing when optimizing the efficiency of the solar systems in which the energy produced is proportional to the incoming solar irradiance, such as planar solar collectors and photovoltaic cells.

Three methods were proposed which are simple, since a basic request for the type of problems formerly discussed is just simplicity and computing speed when analysing climatic data. These methods are :

1. Mean annual relative spectrum of global radia- tion method (curve $\mathrm{G}$ in Fig. 2). The average percentage error over the whole solar spectrum is about $9 \%$.

2. Weighted averages method. It consists in determining the relative spectrum of global radiance for any month from the mean annual relative spectra of direct and diffuse irradiance (curves D and B in Fig. 2) and $F_{0}$, the ratio of diffuse to global radiation for the same day. The estimated error using this procedure is about $4 \%$. The error is always smaller than the one observed when using usual methods, such as the instantaneous spectrum at fixed values of relative air mass. This method, when applied to sloping solar systems introduces a mean error of $5 \%$.

3. Instantaneous spectrum method $\left(m^{*}\right)$.

This method needs to be used when the accuracy in estimating the global relative spectrum must be greater than the one obtained using the second method. In this case the spectrum must be effectively computed but only for an unique value of relative air mass $\left(m=m^{*}\right)$ (see Eq. (24)) which depends on the time of the year. This approximation has an associated mean cumulative error of $1.5 \%$ for horizontal surfaces and $1.8 \%$ for sloping surfaces.

\section{References}

[1] Duffie, J. A. and Beckmann, W. A., Solar Energy Thermal Processes (J. Wiley \& Sons, New York) 1974.

[2] Амato, U., Сuomo, V. and Macchiato, M., The limits of solar photochemical conversion and its dependence on climate. J. Appl. Phys. 54, 5, (1983a) 2738-2749.

[3] Амато, U., Сиомо, V. and Mассhiato, M., The influence of climate on the limits to solar photochemical conversion for systems with internal storage. J. Phys. D : Appl. Phys. 16 (1983b) 1371-1390.

[4] LACIS, A. and HANSEN, E., A Parametrization for the Absorption of Solar Radiation in the Earth's Atmosphere. J. Atm. Sci. 31 (1974) 118-133.
[5] Dave, J., Extensive datasets of the Diffuse Radiation in Realistic Atmospheric Models with aerosols and common absorbing gases. Sol. En. 21 (1978) 361-369.

[6] Kneizys, F. X., Shettle, E. P., Gallery, W. O., Chetwind, J. H., Jr., Abreu, L. W., Selby, J. E. A., Fenn, R. W. and McClatchey, R. A., Atmospheric Transmittance/Radiance : Computer Code LOWTRAN5. AFGL-TR-80-0067, Air Force Geophisics Laboratory, Hanscom AFB, Massachusetts (1980).

[7] Sherry, J. E. and Justus, C. G., A simple hourly clear sky solar radiation model based on meteorological parameters. Sol. En. 30, 5, (1983) 425-431. 
[8] Hoyт, D. V., A model for the calculation of solar global insolation. Sol. En. 21 (1978) 27-35.

[9] Atwater, M. A. and Ball, J. T., A numerical Solar Radiation model based on standard meteorological observations. Sol. En. 21 (1978) 163-170.

[10] Rizzi, R., Serio, C., Guzzi, R. and Francesca, M., Solar Direct Irradiance at the ground : a parametric approach. Sol. En. 25, 1, (1980) 15-20.

[11] IDERIAH, F. J. K., A Model for calculating direct and diffuse solar radiation. Sol. En. 26 (1981) 447-452.

[12] Davies, J. A. and McKay, D. C., Estimating Solar Irradiance and Components. Sol. En. 29, 1, (1982) 55-64.

[13] BöER, K. W., The Solar Spectrum at typical clear sky weather days. Sol. En. 19 (1977) 525-538.

[14] LECKNER, B., The spectral distribution of solar radiation at the Earth's surface - Elements of a model. Sol. En. 20 (1978) 143-150.

[15] Hatfield, J. L., Giorgis, R. B., Jr and FlocChini, R. G., A Simple Solar Radiation Model for computing Direct and Diffuse Spectral Fluxes. Sol. En. 27, 4, (1981) 323-329.

[16] BRINE, D. T. and IQBAL, M., Diffuse and Global Solar Spectral Irradiance under cloudless skies. Sol. En. 30, 5, (1983) 447-453.

[17] Ambrosone, G., Andretta, A., Bloisi, F., Catalanotti, S., Cuomo, V., Silvestrini, V. and Vicari, L., Long Term Performances of Solar Collectors. Appl. Energy 7 (1980) 93-108.

[18] Andretta, A., Barone, G., Brunini, P., Cuomo, V., Francesca, M., Mattarelli, P. and Serio, C., Check of a Computer Program to Calculate Long Term Performance of Solar Flat-Plate Collectors. Appl. Energy 7 (1980) 93-108.

[19] Vigroux, E., Contribution à l'étude expérimentale de l'absorption de l'ozone. Ann. Phys. Fr. 8 (1953) 709.
[20] Guzzi, R. and Scalabrin, G., La Radiazione Solare Diretta e Diffusa - Modelli Fisico Matematici Strumentazione - Applicazioni Energetiche. CNRPFE-LB12, Roma.

[21] Angström, A., Techniques of determining the turbidity of the atmosphere. Tellus 13 (1961) 214-232.

[22] Kondratyev, K. Ya., Radiation in the Atmosphere. Int. Geoph. Series (Academic Press, New York) Vol. 12, 1969 , p. 148.

[23] Temps, R. C. and Coulson, K. L., Solar Radiation incident upon slopes of Different Orientations. Sol. En. 19 (1977) 179-184.

[24] Kluker, T. M.. Evaluation of Models to Predict Insolation on Tilted Surfaces. Sol. En. 23 (1979) 111-114.

[25] LiU, B. Y. H. and JoRdan, R. C., Daily insolation on surfaces tilted toward the equator. ASHRAE J. 3 10 (1961) 53-59.

[26] World Meteorological Organisation, Global Monitoring of the Environment for Selected Atmospheric Constituents. EPA/USDC/NOAA, Washington (1980).

[27] Bartoli, B., Catalanotti, S., Cuomo, V., Francesca, M., Serio, C., Silvestrini, V. and Troise, G., Statistical Correlation between Daily and Monthly Averages of Solar Radiation Data. Nuovo Cimento 2C (1979) 222-234.

[28] Bartoli, B., Coluzzi, B., Cuomo, V., Francesca, M. and Serio, C., Autocorrelation of Daily Global Solar Radiation, Nuovo Cimento 4C (1981) 113-122.

[29] Andretta, A., Bartoli, B., Coluzzi, B., Cuomo, V., Francesca, M. and Serio, C., Global Solar Radiation Estimation from Relative Sunshine Hours in Italy. J. Appl. Meteor. 21, 10, (1982) 1377-1384.

[30] KASTEN, F., A new table and approximate formula for relative optical air mass. Arch. Meteorol. Geophys. Bioklimatol. Ser. B 14 (1966) 206-223. 